\title{
Drug patent plan gets mixed reviews
}

\section{GlaxoSmithKline's bid to tackle neglected diseases receives a muted response from the rest of the industry.}

Proposals to radically change the way the drug industry approaches neglected tropical diseases have prompted intense debate within the sector.

Andrew Witty, chief executive of GlaxoSmithKline (GSK), outlined the suggestions in a speech on 13 February at Harvard Medical School in Boston, Massachusetts. He committed GSK - the world's second-largest pharmaceutical company by sales - to sharing some of its patents to boost research into neglected diseases, and to making its drugs available more cheaply in the very poorest countries.

He also offered to open up GSK's research centre for neglected diseases at Tres Cantos in Spain to other researchers, companies and governments. The aim would be to foster a global public-private network to supplant the present fragmented research efforts on the most neglected diseases, such as sleeping sickness, visceral leishmaniasis and dengue fever.

Reactions from scientists and public-health experts have ranged from wildly enthusiastic to deeply sceptical. But it is undoubtedly a pioneering move, particularly for a firm that just a decade ago joined 38 other drug companies in suing the South African government to try to stop it making cheap antiHIV drugs.

"That was the low-water mark for multinationals and global health," says Peter Singer, an expert in public health at the University of Toronto in Canada. "This announcement may not yet be the high-water mark, but it is incontrovertible evidence that the tide has turned. It sends a clear signal that GSK wants to be part of the solution and not part of the problem."

The most innovative aspect of GSK's proposal is the creation of a 'patent pool' for drugs and manufacturing processes related to neglected tropical diseases. Researchers and companies, including manufacturers of generic drugs, would be able to license participants' patents from the pool for free to develop new treatments for neglected diseases in the world's 50 least-developed countries (LDCs).

"A patent pool giving access to molecule libraries and information from different groups

\section{OPENING ACCESS}

A selection of other drug firms' efforts on neglected tropical diseases.

Pfizer

- Donates medicines through individual deals with governments and nongovernmental organizations - Mobilize Against Malaria initiative in Ghana, Kenya and Senegal to improve access to malaria treatment.

- International Trachoma

Initiative has donated

54 million antibiotic treatments to patients in 13 countries (see Nature 457, 772-773; 2009).

Hoffmann-La Roche - Expert assistance given to the Medicines for Malaria Venture, a non-profit organization aimed at discovering malaria drugs. - Donated to the Brazilian government all rights and technology to manufacture benznidazole for the treatment of Chagas' disease.

- Technology-transfer initiative helps developing countries produce their own generic HIV medicines.

\section{Novartis}

- Provides not-for-profit treatments for dengue fever, tuberculosis and malaria in countries where endemic.

- Novartis Institute for Tropical Diseases in Singapore established in 2002 as a public-private partnership with the Singapore Economic Development Board.

- Novartis Vaccines Institute for Global Health in Siena, Italy, established in 2007 to develop vaccines for neglected diseases.
Sanofi-aventis

- Sells key medicines at cost to governments and aid agencies. - In 2007 spent $€ 14$ million (US\$18 million) on improving access to medicines in developing countries; $€ 4$ million on neglected tropical diseases; and more than $€ 20$ million on R\&D for malaria, leishmaniasis and tuberculosis.

Bayer

- Donates drugs for sleeping sickness and Chagas' disease to the World Health Organization. - Donates antibiotics for tuberculosis to the Global Alliance for TB Drug Development.

- Bayer CropScience donates mosquito nets and insecticides in key countries.

N.G.

\section{Industrial unease}

But several other drug companies contacted by Nature were lukewarm about the idea. French firm Sanofi-aventis says that the proposals are "too vague" to comment on, and Swiss-based Novartis "does not consider intellectual property as an obstacle to access to medicines", according to company representatives.

In principle, Bayer in Germany is not against the idea of pooling intellectual property, says the company's spokeswoman, Denise Rennmann. But it would prefer an industry-wide approach to be agreed multilaterally, she adds - something that the World Health Organization and the International Federation of Pharmaceutical Manufacturers are already discussing. Many companies highlighted their own efforts to improve access to drugs for neglected diseases (see 'Opening access').

The patent-pool proposal has also sparked controversy because it excludes GSK's HIV patents, as the company feels that there is already enough research in this area. That is hotly contested by Michelle Childs, director of policy and advocacy at Médecins Sans Frontières' Campaign for Access to Essential 
Medicines, who says that there is still a great need for new antiretroviral combinations and formulations for children.

However, GSK's HIV patents could yet dive into a different pool. UNITAID, an international organization that negotiates lower drug prices, hopes to launch a patent pool by the end of this year that would allow companies to license their AIDS drugs in return for royalties. Ellen 't Hoen, UNITAID's senior adviser on intellectual property, says that although no companies have yet signed up, several have expressed interest, including GSK.

There is a sound incentive for companies to join such patent pools. Countries with large populations of sick patients are increasingly likely to use their rights under TRIPS, the World Trade Organization's intellectual-property agreement, to issue compulsory licences, allowing them to produce generic copies of patented drugs at low royalties.

Western drug companies fret that such licences could limit their opportunities in what they see as their biggest future growth markets: the well-off elites in emerging economies such as India, China or Brazil. Preserving these markets may explain why GSK has limited its proposals to the LDCs, says Brook Baker, an expert on health and human rights at Northeastern University in Boston.

Witty also announced that GSK would cut the prices of all its medicines in the LDCs to no more than $25 \%$ of their prices in the richest countries. But the focus on the LDCs means that these cuts, and the patent pool, will not benefit the vast number of poverty-stricken people living in middleincome countries, says Baker. According to the World Bank, more people live on less than $\$ 2$ per day in India than in all of subSaharan Africa.

Despite the cuts, GSK's drugs will still be unaffordable to most poor people, he adds. And if generic producers can only use the patent pool to produce drugs for the LDCs, they will not be able to get the economies of scale they need to sell drugs cheaply enough.

"When Glaxo and others announced at the start of the decade that they would cut the cost of HIV drugs by $70 \%$, initially we thought 'this is a big deal," says Childs. "But they were still unaffordable. It was only when generic manufactures brought prices down $99 \%$ that we saw wide access to drugs."

Declan Butler

Additional reporting by Natasha Gilbert

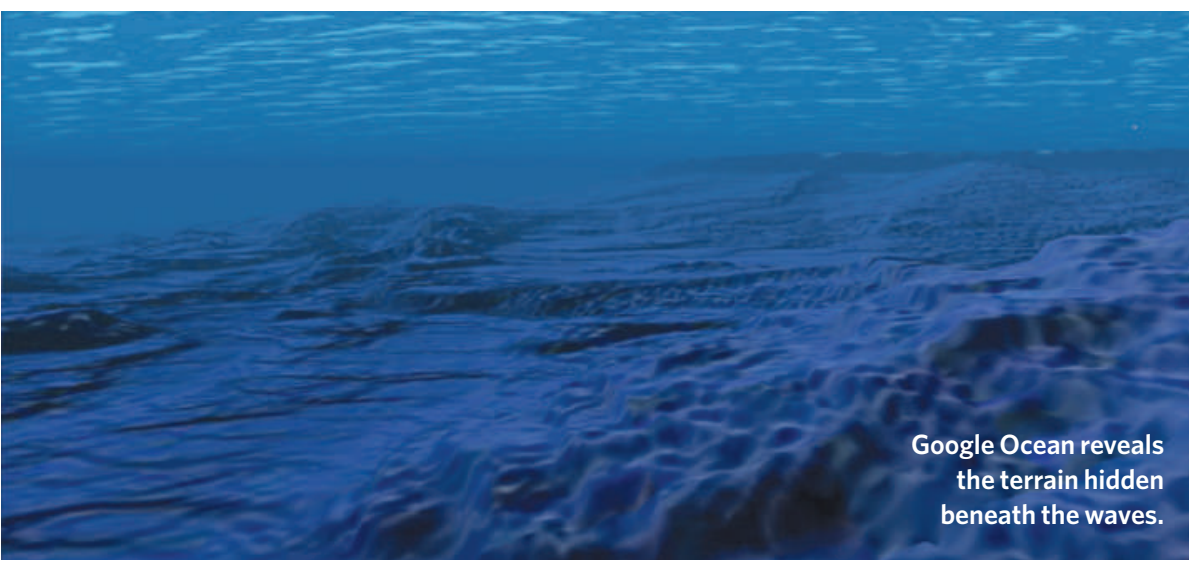

\section{Seabed images create waves}

Fly to coordinates N0 E94.75 in Google Ocean, the visualization program launched this month that renders marine environments in unprecedented detail, and you'll see something that's definitely not in the real ocean: the initials 'DTS/SIO'. This is the mark of geophysicist David T. Sandwell of the Scripps Institution of Oceanography in La Jolla, part of the University of California, San Diego (UCSD), who uses the initials here and elsewhere to mark vast areas of the ocean that remain uncharted.

The initials are also a reminder of the people and institutions behind the data and how they can lose out on financial gain as public assets enter the corporate world. More than a decade ago, Sandwell and Walter Smith of the National Oceanic and Atmospheric Administration in Silver Spring, isn't doing squat." Maryland, developed a way to convert gravity and ocean-depth data from satellite missions and research cruises into a bathymetric map of the sea floor. Google Ocean incorporates that method - which Sandwell copyrighted for UCSD — without compensation.

Many researchers have praised Google's visualizations such as Google Earth and Google Mars. "Scientists want to see their data published and used by the world," says Steve Miller, project manager for Google Ocean at the California-based company headquartered in Mountain View. The programs incorporate public-domain data from non-profit organizations and agencies such as NASA.

But some question whether institutions - whose researchers often develop sophisticated ways of using such data - are losing out. "The marketplace is taking the technology and the university isn't doing squat," says Gideon Markman, a management scholar at Colorado State University in Fort Collins. Jeff Chester, a social scientist who directs the Center for Digital Democracy in Washington DC, goes further: "In this case, it looks like the university was digitally fleeced."

Miller says that Google talked last summer with UCSD and Sandwell about incorporating the technology. "There were some legal questions," he says. "But we are comfortable." And William Decker, UCSD's technology-transfer official on the case, says, "we followed the process we always do to get appropriate fair value".

Sandwell wants other researchers to use his bathymetric map, and asks commercial providers to contact him before use. Oil and gas companies such as ExxonMobil have done so and funded his research. But Google didn't contact Sandwell when it first started using an earlier version of the bathymetry

in 2005, and he raised the issue with the company last year as it was working on its oceans system.

Tony Haymet, the Scripps's director who led discussions with Google, acknowledges that there were no negotiations for compensation. Asked why the university didn't push to receive anything when state universities are facing major financial difficulties, Haymet responded: “That's a good question."

Last August, the US National Geophysical Data Center in Boulder, Colorado, pulled a version of Sandwell's technology from its website in part because of the copyright issue.

So far, all that Sandwell has received in return for his work is a year's worth of Google Earth Pro software - normal cost US $\$ 400$ for his classes. He is now applying to a Google foundation for funds to support a postdoctoral research position in oceanography.

Rex Dalton 